\title{
Qualificação profissional para pessoas com deficiência intelectual: perspectiva dos professores
}

\author{
Professional qualification for people with intelectual disabilities: teachers \\ perspective
}

Cualificación professional de las personas con discapacidad intelectual: la perspectiva de los maestros

\footnotetext{
* Mariela Cristina de Aguiar Costa

Mestre pela Universidade Federal de São João del-Rei, São João del-Rei, Minas Gerais, Brasil. marielacac@gmail.com
}

\section{** Maria Nivalda de Carvalho-Freitas}

Professora doutora da Universidade Federal de São João del-Rei, São João del-Rei, Minas Gerais, Brasil. nivalda@ufsj.edu.br

\section{*** Marina Carvalho Freitas}

Graduada pela Universidade Federal de São João del-Rei, São João del-Rei, Minas Gerais, Brasil. marifreitas_11@hotmail.com

Recebido: 13 de novembro de 2017

Aprovado: 22 de outubro de 2018

\section{RESUMO}

Este estudo investigou a percepção dos professores acerca da qualificação profissional para pessoas com deficiência intelectual oferecida nas APAEs de Minas Gerais. Realizouse um estudo com uma amostra de 47 professores de 21 APAEs do Estado por meio do método quantitativo - survey, cuja análise envolveu técnicas estatísticas, como: análise descritiva e análise do coeficiente de correlação de Spearman. Também foi utilizado o método qualitativo, por meio de entrevistas semiestruturadas, em três instituições apaeanas com nove professores, transcritas e submetidas à análise de conteúdo. Os resultados indicam que as oficinas profissionalizantes para pessoas com deficiência intelectual oferecidas nas APAEs contribuem em vários aspectos para a ocupação e o desenvolvimento dos alunos. Verificou-se também que o processo de qualificação profissional está associado à necessidade das famílias em relação ao Benefício de Prestação Continuada e às concepções de deficiência dos professores, indicando que as discussões sobre qualificação profissional de pessoas com deficiência intelectual envolvem outros fatores para além das ações de formação propriamente ditas.

Palavras-chave: Deficiência intelectual; Benefício de prestação continuada; Concepções de deficiência. 


\section{ABSTRACT}

This study investigated the teacher's perception about the professional qualification for people with intellectual disabilities teaching in the Associations of Parents and Friends of the Exceptional (APAEs) of Minas Gerais. The study was carried out with a sample of 47 teachers from 21 APAEs of the State through the quantitative-survey method, whose analysis involved statistical techniques, such as: descriptive analysis and analysis of the Spearman correlation coefficient. The qualitative method was also used, through semistructured interviews, in three APAEs units with nine teachers, transcribed and submitted to content analysis. The results indicate that the professional qualification for people with intellectual disabilities promoted by the APAEs contribute in several aspects to the occupation and the development of the students. It was also verified that the professional qualification process is associated to the families' need for the Benefit from Continued Provision and to teacher's conceptions of disabilities, indicating that the discussions about professional qualification of people with intellectual disability involve factor other than actions of qualification itself.

Keywords: Intellectual disabilities; Benefit from continued provision; Conceptions of disability.

\section{RESUMEN}

Este estudio investigó la percepción del maestro sobre la calificación profesional para personas con discapacidad intelectual enseñando en las Asociaciones de Padres y Amigos de lo Excepcional (APAEs) de Minas Gerais. El estudio se realizó con una muestra de 47 docentes de 21 APAEs del Estado a través del método de la encuesta cuantitativa, cuyo análisis involucró técnicas estadísticas, tales como: análisis descriptivo y análisis del coeficiente de correlación de Spearman. El método cualitativo también se utilizó, a través de entrevistas semiestructuradas, en las tres unidades APAEs con nueve docentes, transcrito y sometido a análisis de contenido. Los resultados indican que la calificación profesional para personas con discapacidad intelectual promovida por las APAEs contribuye en varios aspectos a la ocupación y al desarrollo de los estudiantes. También se verificó que el proceso de calificación profesional está asociado a la necesidad de las familias de obtener beneficios de la provisión continua y a las concepciones de discapacidad de los docentes, lo que indica que las discusiones sobre la calificación profesional de las personas con discapacidad intelectual implican factores distintos de las acciones de capacitación.

Palabras clave: Discapacidad intelectual; Beneficios de la provisión continua; Concepciones de discapacidad.

\section{Introdução}

O Brasil embora disponha de um conjunto de leis voltadas para a assistência e para a garantia ao trabalho das pessoas com deficiência, as informações sobre as taxas de emprego dessa população indicam a existência de dificuldades nesse processo de inclusão. 
http://dx.doi.org/10.5902/1984686X29957

Em 2016, os dados da Relação Anual de Informações Sociais (RAIS) revelaram um total de 391 mil vínculos empregatícios ativos de trabalhadores com deficiência, o que representa $0,85 \%$ do total de pessoas com deficiência no país. Do total de trabalhadores brasileiros com deficiência que possuem carteira assinada, somente $8,2 \%$ são representados por pessoas com deficiência intelectual (MINISTÉRIO DO TRABALHO, 2017).

Algumas questões têm sido apontadas como possíveis explicações para as dificuldades de contratação de pessoas com deficiência, dentre elas: (a) a predominância de baixa qualificação profissional dessas pessoas (SILVA; PALHANO, 2001; TANAKA; MANZINI, 2005; ARAÚJO; SCHMIDT, 2006; RIBEIRO; CARNEIRO, 2009); (b) a insegurança da perda do Benefício de Prestação Continuada (BPC) e o desconhecimento da possibilidade de reavê-lo por parte das pessoas com deficiência e de seus familiares (COSTA et al, 2011); e (c) as concepções que empregadores e a sociedade, em geral, têm sobre a deficiência influenciando nas possibilidades e limites da inclusão destas pessoas (DINIZ; BARBOSA; SANTOS, 2010; SANTOS, 2010; SASSAKI, 2003).

Do ponto de vista da qualificação profissional para pessoas com deficiência intelectual a Associação de Pais e Amigos dos Excepcionais (APAE) é a instituição com maior trajetória de desenvolvimento de programas de educação profissional, com o objetivo de oferecer qualificação para seus alunos, por meio de oficinas profissionalizantes, preparando-os para a inclusão no mercado de trabalho (FENAPAEs, 2006, 2011; UNIAPAE, 2017).

Segundo o Decreto n. 1.330 (1994), o Benefício de Prestação Continuada é a garantia de um salário mínimo mensal à pessoa com deficiência e ao idoso com 65 anos ou mais, que comprovem não possuir meios de prover a própria manutenção e nem de tê-la provida por sua família, cuja renda mensal de seus integrantes, dividida pelo número destes, seja inferior a $1 \frac{1}{4}$ (um quarto) do salário mínimo por pessoa.

No que se refere às concepções de deficiência, Carvalho-Freitas e Marques (2007), a partir de extensa revisão de literatura, identificaram as principais matrizes de pensamento que moldaram e legitimaram a distinção das pessoas com deficiência na sociedade. Tais matrizes interpretativas são modalidades relativamente estáveis e organizadas de pensamento, ancoradas em concepções de homem, de mundo e de sociedade que se materializam nas ações privilegiadas pelas pessoas quando em contato com pessoas com deficiência. São elas: a deficiência vista como fenômeno espiritual, caracterizada pela 
http://dx.doi.org/10.5902/1984686X29957

atribuição de uma origem metafísica e uma manifestação de desejos ou castigos divinos; a normalidade, como matriz de interpretação, tem a norma como padrão de avaliação, sendo a deficiência considerada um "desvio" ou "doença" que necessita de cuidados especiais dos profissionais da saúde; a inclusão, como matriz de interpretação, que desloca a deficiência de um problema individual para um problema social, baseada no pressuposto de que a sociedade tem que se adaptar para incluir todos; e a matriz de interpretação técnica da deficiência, que se materializa quando a diversidade passa a ser um recurso a ser gerido nas organizações, sendo contempladas as práticas sociais e organizacionais que viabilizem a participação e inclusão das pessoas com deficiência. Esses pesquisadores concluíram que a caracterização das concepções de deficiência é um fenômeno sóciohistórico e que se ancora no pressuposto psicológico de que o homem precisa criar explicações para a realidade na qual está inserido (CARVALHO-FREITAS; MARQUES, 2010).

Tendo esse cenário por referência, este estudo visou a identificar, a partir da percepção de professores, como ocorria a qualificação profissional para pessoas com deficiência intelectual oferecida nas APAEs do estado de Minas Gerais - Brasil e o impacto tanto do BPC quanto das concepções de deficiência dos professores na inclusão no trabalho dos alunos.

\section{Método}

Os recursos metodológicos utilizados para a coleta e análise de dados foram quantitativos e qualitativos. Considerando que, no estado de Minas Gerais, existem 414 APAEs e, destas, 251 possuem oficinas profissionalizantes, foram contatadas, via e-mail, as instituições que dispunham de oficinas, uma vez que a população-alvo desta pesquisa consistia dos professores responsáveis por estas. Após o convite para participação na pesquisa, 47 profissionais de 21 cidades do Estado retornaram o e-mail, aceitando participar do estudo. Com estes, foi realizado um survey de desenho transversal, na primeira fase do estudo.

Todas as 47 professoras participantes do estudo são do sexo feminino, $76,5 \%$ têm idade acima de 41 anos e 89,4\% possuem, no mínimo, o ensino superior completo, sendo $39,4 \%$ destes pós-graduados, o que evidencia alto grau de instrução e qualificação dos professores. Mais da metade $(55,5 \%)$ dos professores coordenam a oficina há menos de 
http://dx.doi.org/10.5902/1984686X29957

cinco anos e 24,4\% trabalham na mesma oficina há mais de 11 anos e 55\% das oficinas não têm nenhum aluno no mercado formal de trabalho.

Em uma segunda etapa da pesquisa, uma amostra de nove professores foi entrevistada, sendo três professores de três municípios diferentes, escolhidos por se caracterizarem dentro do perfil médio identificado na primeira etapa da pesquisa e em razão da possibilidade de acesso aos sujeitos. Essas professoras receberam nomes fictícios, pois consentiram em participar da pesquisa mantendo o anonimato.

Os instrumentos utilizados em ambos os procedimentos foram submetidos a um painel de especialistas, visando a avaliar a adequação dos instrumentos, e a um teste piloto com o objetivo de verificar se as questões eram de fácil compreensão para os entrevistados. Na primeira etapa da pesquisa, os professores responderam a um questionário online contendo: questões relacionadas ao perfil sociodemográfico dos profissionais, além de conter dados sobre os alunos e a turma que os professores coordenavam, com o intuito de melhor caracterizar a população do estudo. Logo após, seguiu-se um total de 30 questões, divididas em três partes, que abrangeram as seguintes categorias:

- Gestão das oficinas de qualificação profissional: refere-se ao funcionamento de cada oficina profissionalizante na APAE. Dispõe sobre como a oficina foi criada, como os alunos foram selecionados para participar, a venda dos produtos confeccionados, o suporte oferecido, a formação dos professores para executarem essa função, bem como a efetividade da qualificação profissional oferecida (colocação no trabalho e dificuldades encontradas).

- BPC: refere-se ao impacto deste na formação profissionalizante dos alunos e nas famílias, bem como o conhecimento dos professores acerca desta concessão do governo.

- Inventário de Concepções de Deficiência em Situações de Trabalho (ICD-ST): com o objetivo de identificar as concepções de deficiência desses docentes. O ICD-ST é constituído por 19 questões que abrangem fatores relacionados às matrizes espiritual, da normalidade, da inclusão, percepção de desempenho, percepção do vínculo e percepção dos benefícios da contratação. Esses três últimos fatores contemplam a matriz de interpretação técnica da deficiência (CARVALHO-FREITAS, 2012).

A análise dos dados quantitativos, obtidos pelo questionário, envolveu a utilização de técnicas estatísticas, a partir do programa SPSS for Windows (Statistical Package for Social Sciences), tais como: estatística descritiva e análise da correlação de Spearman. 
http://dx.doi.org/10.5902/1984686X29957

Na segunda etapa da pesquisa, nove docentes responderam a uma entrevista visando aprofundar a compreensão dos aspectos investigados. As entrevistas foram gravadas e transcritas. A análise qualitativa dessas entrevistas foi realizada utilizando-se o referencial da análise de conteúdo, definida por Bardin (1994, p. 38) como "um conjunto de técnicas de análise das comunicações, que utiliza procedimentos sistemáticos e objetivos de descrição de conteúdo das mensagens". A análise de conteúdo se organiza em três momentos: pré-análise, exploração do material e tratamento dos resultados (BARDIN, 1994) e visou identificar os aspectos investigados na presente pesquisa: qualificação profissional, BPC e concepções de deficiência dos docentes.

\section{Resultados e discussão}

Nessa seção serão apresentadas as categorias analisadas: qualificação profissional, impacto do BPC e concepções de deficiência dos professores. Os dados quantitativos e qualitativos serão apresentados conjuntamente uma vez que as mesmas categorias foram objeto de investigação das duas etapas da pesquisa.

\section{Gestão das oficinas de qualificação profissional}

Em todas as oficinas as atividades ensinadas estavam circunscritas a funções operacionais, ou seja, atividades voltadas para trabalhos manuais. As professoras entrevistas, em geral, relatam que a realização de algum trabalho, ainda que predominantemente manual e repetitivo, é uma forma de possibilitar um maior pertencimento social dos alunos e a diminuição do preconceito por parte da sociedade em geral.

Das 40 professoras que responderam as questões sobre a alfabetização dos alunos participantes de oficinas, oito afirmaram não haver nenhum aluno alfabetizado em sua turma e 23 professoras indicaram que o índice de alfabetização não ultrapassa 40\%, ratificando os dados encontrados no estudo de Paiva Silva e Ribeiro (2011) sobre a baixa escolaridade desse público. Uma professora entrevistada, Ana, acompanhada da coordenadora do ensino profissionalizante de uma das APAEs, relata sua opinião sobre o trabalho para as pessoas com deficiência intelectual:

Pela falta de alfabetização é complicado o mercado de trabalho para eles. Não é que eles não tenham condições, eles têm condições, têm condições de pegar um trabalho assim braçal e tudo, mas depende, 
http://dx.doi.org/10.5902/1984686X29957

muita coisa depende da leitura, escrita, coisa que depende da alfabetização, é onde já complica para eles.

Embora 85\% das professoras participantes afirmem que o trabalho a ser ensinado foi escolhido de acordo com o interesse dos alunos naquela atividade e $81 \%$ afirmem que os alunos foram questionados sobre seus interesses na oficina, a maioria das professoras (57\%) também respondeu que, na criação da oficina, a atividade a ser ensinada foi escolhida conforme a formação da professora disponível. Outras $66 \%$ respondentes também concordaram que a oficina foi criada de acordo com as possibilidades de trabalho disponíveis na cidade. A proposta das oficinas é de que as possibilidades de trabalho disponíveis na cidade e região sejam avaliadas e que os professores sejam amplamente capacitados para esse trabalho específico, a fim de que a qualificação dos alunos seja efetiva e não se torne, na prática, uma espécie de terapia ocupacional. No entanto, admitese que podem ocorrer obstáculos em diversos aspectos, como: dificuldades financeiras, falta de capacitação dos professores para determinada atividade, falta de maquinário e equipamentos disponíveis, bem como de materiais. Todas estas questões podem, segundo as professoras, dificultar a execução dos objetivos e ideais propostos no programa de qualificação da APAE. Porém, quando questionados quanto ao suporte material, psicológico, capacitação técnica e satisfação dos professores, os índices foram de $66 \%$ de satisfação, indicando que essas dificuldades impactam grande parte o trabalho de $44 \%$ desses docentes.

Quanto à efetividade das oficinas, observou-se uma contradição entre o alto índice de respostas acerca de os objetivos da oficina serem atingidos (34\% responderam "frequentemente" e 55\% "de vez em quando") e - simultaneamente - a alta frequência de respostas concordantes com a afirmativa de que a oficina tem funcionado mais como terapia ocupacional e também com o fato de os alunos permanecerem muitos anos nas mesmas (64\% afirmaram "frequentemente"). Observa-se que as professoras reconhecem que somente em um terço dos casos as oficinas são realmente efetivas e que, a maior parte dos alunos não se desvincula das oficinas e não ingressa no mercado de trabalho.

Das professoras participantes, $89 \%$ afirmaram que os produtos confeccionados nas oficinas profissionalizantes são vendidos. Entretanto, quanto ao destino do dinheiro arrecadado, 74\% disseram que é a direção da APAE local que define o que será realizado com o mesmo, não havendo discussão com os alunos sobre a melhor destinação dos recursos arrecadados, o que contribuiria com a promoção de autonomia defendida pela 
http://dx.doi.org/10.5902/1984686X29957

instituição. Nas entrevistas esse fator foi mencionado pela professora Auxiliadora, de uma das APAEs visitadas:

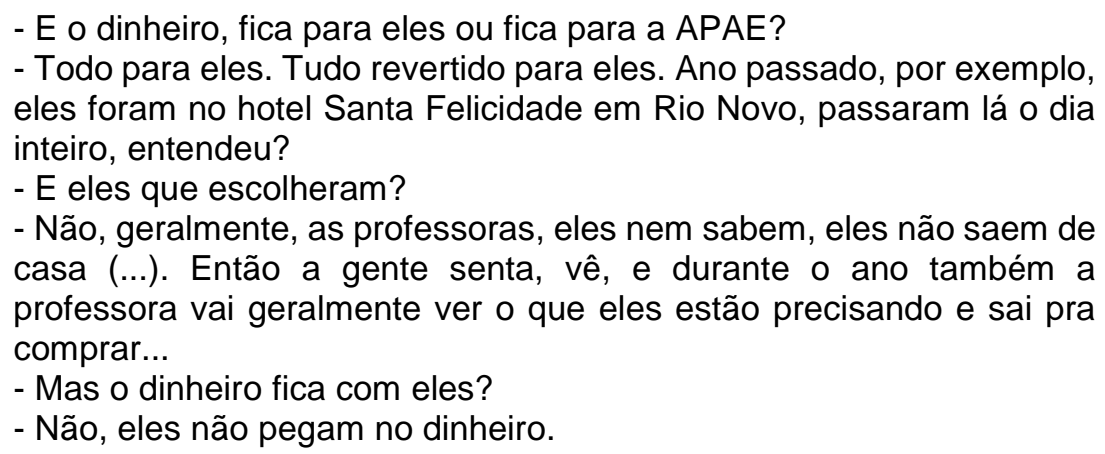

Este tipo de ação contribui para a não valorização do processo de tomada de decisão pelas pessoas com deficiência intelectual, neste aspecto institucional, deixando de utilizar uma oportunidade de prepará-las para as vivências fora da instituição apaeana, o que faz com que a instituição deixe de estimular, neste ponto, a autonomia a ser desenvolvida pelos alunos. Na pesquisa realizada por Costa et al (2011, p. 209) em cinco APAEs de Minas Gerais, as autoras afirmam que as ações de destinação do dinheiro dos produtos explicitam uma contradição das instituições: "o reconhecimento explícito do trabalho dos alunos e o não-reconhecimento da possibilidade de esses alunos decidirem a forma de aplicação desses recursos", o que vai ao encontro dos resultados deste estudo.

Conforme $81 \%$ das professoras, o acompanhamento do trabalho das pessoas com deficiência intelectual já inseridas no mercado de trabalho é realizado "frequentemente". Segundo 57\% das participantes, "frequentemente" a preparação para o trabalho dessas pessoas é avaliada como positiva pelos empregadores e $23 \%$ acreditam que "de vez em quando" as empresas avaliam positivamente essa preparação. Por outro lado, outros estudos indicam que a baixa qualificação profissional ou a não-equiparação das atividades ensinadas com as vagas disponíveis são apontadas, pelos empregadores, como alguns dos principais motivos para a não-contratação de pessoas com deficiência, segundo Tanaka e Manzini (2005), Araújo e Schmidt (2006), Ribeiro e Carneiro (2009).

\section{Benefício de Prestação Continuada}

Das 42 professoras que responderam a esse item, 23 têm mais da metade dos alunos da turma favorecidos com esse benefício e 17 indicam ter mais de $20 \%$ de beneficiários. Observou-se que 85\% das professoras acreditam que o BPC é considerado um entrave à busca de trabalho formal por parte das pessoas com deficiência intelectual, embora $74 \%$ 
http://dx.doi.org/10.5902/1984686X29957

afirmem ter conhecimento da possibilidade de retorno do benefício em caso de perda do emprego. Conforme o Decreto n. 6.214, Art. 25, de 2007 a suspensão do Benefício de Prestação Continuada concedido à pessoa com deficiência não impede uma nova concessão do benefício se os requisitos exigidos forem atendidos. Para as professoras entrevistadas, o BPC é o principal aspecto na dificuldade de inserção do aluno, na realidade delas.

Em uma das APAEs, a professora Dalva explica que sua oficina profissionalizante é mais voltada para o trabalho informal em função de todos os alunos da sala receberem o BPC. Segundo ela, para trabalhar com carteira assinada, "a gente prefere selecionar os que não têm benefício". Quando questionada sobre a possibilidade de conseguir o benefício novamente em caso de perda do emprego, a professora demonstra ter conhecimento da lei:

\footnotetext{
Dizem que, hoje em dia, me falaram o seguinte, que eles têm a oportunidade de voltar. (...) Só que demora, às vezes. Os pais têm medo, entendeu, então, assim, a gente sabe que as coisas são lentas (...), tem uma burocracia, então a gente prefere, nesse momento, trabalhar com o que a gente sabe que pode.
}

Em outra APAE visitada, a professora Moema afirma que sua oficina é mais voltada para trabalhos domésticos, como cuidar da casa, cozinhar, mas não há foco de inserção no mercado de trabalho formal. Segundo ela, "porque tem muitas que têm benefício, nem podem trabalhar fora, porque senão perde esse benefício, mas pode trabalhar em casa".

Essa forma de entender a aplicação da lei demonstra um ceticismo em relação à tempestividade na garantia dos direitos das pessoas de baixa renda (contempladas pelo BPC), com a presença de um conjunto de procedimentos legais que não leva em consideração a dependência de muitas famílias desse tipo de recurso, gerando como contrapartida, um temor das pessoas com deficiência e das famílias de buscar o ingresso no mercado de trabalho, conforme indicado em outras pesquisas (COSTA et al, 2011; ALMEIDA; CARVALHO-FREITAS; MARQUES, 2008).

Por outro lado, há um reconhecimento da importância da legislação na garantia dos direitos das pessoas com deficiência, por exemplo, no que se refere à Lei de Cotas. O relato abaixo, da professora Suzana, explicita a opinião da maioria das professoras no que se refere à possibilidade de inclusão no mercado formal de pessoas com deficiência intelectual. 
http://dx.doi.org/10.5902/1984686X29957

É difícil, você aceitar e conhecer, porque, às vezes, não é nem aceitar, é conhecer a capacidade deles, porque eles são capazes, mas falta essa orientação e falta essa busca de orientação por parte das empresas, porque não são esclarecidas pra isso. (...). Tem pessoas mais fáceis de serem incluídas, de serem empregadas lá, então eu acho que a Lei veio a beneficiar e é através da lei que eles conseguem essa inclusão.

Embora a questão das políticas afirmativas seja objeto de controvérsia, concorda-se com Cardoso et al (2017) que a legislação ainda é um mecanismo importante para garantir a equidade quando estão em jogo os interesses de grupos muito diferenciados em termos econômicos, culturais e políticos.

\section{Concepção de deficiência dos professores}

Nos resultados obtidos a partir do Inventário de Concepções de Deficiência em Situações de Trabalho (ICD-ST), a maioria das professoras discorda que a deficiência represente uma manifestação divina, de origem transcendental (matriz espiritual de concepção de deficiência), embora $36,4 \%$ acredite em uma missão espiritual vinculada à deficiência. Como implicações decorrentes dessa crença podem coexistir sentimentos de piedade com relação às pessoas com deficiência (CARVALHO-FREITAS, 2009), com possível impacto negativo para a formação profissional dessas pessoas.

Quanto à concepção baseada nos pressupostos da normalidade, embora tenha sobressaído o número de professoras que concordam com essa concepção, os índices ficaram divididos: 56,5\% concordam e 43,5\% discordam dessa perspectiva. Esta divergência de opinião pode estar relacionada ao processo de transição dos valores e missão da APAE, criada numa época em que a concepção médica da deficiência e as atitudes assistencialistas prevaleciam, mas que, atualmente, busca desenvolver os trabalhos tendo como referência de valor a ser alcançado a construção de autonomia e o respeito aos direitos das pessoas com deficiência. Mesmo assim, constata-se, na prática (como a relação com o dinheiro arrecadado da venda dos produtos confeccionados nas oficinas), que a visão da deficiência como desvio da normalidade, necessitada de cuidados especiais, ainda é forte entre as profissionais da área, não sendo creditada, aos alunos, a possibilidade de autonomia nas situações cotidianas de trabalho.

Ao analisar a matriz técnica e seus fatores (desempenho, vínculo e benefícios da contratação), constatou-se que a deficiência, como recurso a ser gerenciado dentro das organizações, tem tido uma percepção positiva das professoras, principalmente em relação 
http://dx.doi.org/10.5902/1984686X29957

à percepção dos benefícios da contratação $(84,4 \%)$ e do desempenho no trabalho das pessoas com deficiência $(82,2 \%)$.

Observou-se, majoritariamente, entre as professoras das oficinas profissionalizantes das APAEs, a concordância com a concepção baseada nos pressupostos da inclusão (79\%). Embora coexistam a matriz espiritual e a concepção da normalidade, a predominância da matriz inclusiva da deficiência, neste estudo, corrobora os resultados de outras pesquisas da área que também identificaram, porém em organizações, uma prevalência da concepção inclusiva (CARVALHO-FREITAS, 2009; SUZANO, 2011). A adoção desta perspectiva, por parte das professoras, pode ser um reflexo de campanhas institucionais ou das que, eventualmente, são veiculadas em grandes meios de comunicação, ao longo dos anos, e que contribuem para as mudanças sociais e culturais em relação às pessoas com deficiência. Essa também é uma tendência nas pesquisas mais atuais, que indicam a necessidade de se modificar as condições de trabalho para ser acessível a todos (ANGELA, 2015; BRUCKER; HOUTENVILLE, 2015).

$\mathrm{Na}$ análise quantitativa dos resultados, foram realizadas correlações entre as concepções de deficiência e aspectos relacionados à gestão das oficinas e à legislação, tendo sido identificado os seguintes resultados:

- Quanto maior é a crença de que contratar pessoas com deficiência gera benefícios para as organizações, maior é o índice de concordância de que as oficinas profissionalizantes das APAEs têm conseguido atingir seu objetivo de qualificar as pessoas com deficiência intelectual para o trabalho (Spearman $=0,363, p<0,05$ ). Partindo do pressuposto de que as crenças influenciam tanto na atitude quanto no comportamento das pessoas, verifica-se a relevância de uma crença positiva dos professores nos benefícios do trabalho das pessoas com deficiência para as organizações, uma vez que essas crenças terão impacto nas ações de qualificação dessas pessoas nas oficinas profissionalizantes. Essa constatação abre novas possibilidades de investigação visando identificar ações que contribuem para o sucesso dessas oficinas, visando sistematizar os resultados de forma a disseminar esse conhecimento e contribuir para a maior inclusão no trabalho.

- Quanto maior a concepção da deficiência pela matriz espiritual, que vê a deficiência como vontade divina, de origem metafísica, maior a percepção de que a Lei de Cotas é preconceituosa, na medida em que trata as pessoas com deficiência de maneira diferente das pessoas sem deficiência, (Spearman $=0,369, p<0.05$ ). Essa constatação identifica a importância de reflexões permanentes com os professores sobre as concepções que eles 
http://dx.doi.org/10.5902/1984686X29957

têm de deficiência e sobre a Lei de Cotas, visando minimizar possíveis impactos dessas crenças no trabalho cotidiano desses professores. Carvalho-Freitas (2009) identificou que a predominância dessa matriz espiritual gera sentimentos de piedade em relação às pessoas com deficiência e dificuldades no manejo do desempenho dessas pessoas.

- Quanto maior a tendência de acreditar na concepção de inclusão (Spearman = 0,374, $\mathrm{p}<0.05$ ) e maior a crença no bom desempenho das pessoas com deficiência no trabalho (Spearman $=0,406, p<0.01$ ), maior a percepção de que a Lei de Cotas favorece a contratação de pessoas com deficiência. Essas correlações indicam a importância de se pensar a deficiência tendo como referência o Modelo Social (BARNES; MERCER; SHAKESPEARE, 2005), que é a perspectiva da inclusão que desloca o foco da deficiência das pessoas para as deficiências da sociedade em ser um espaço para todos, o que impacta na valorização de ações, como a Lei de Cotas, como uma forma de minimizar as desigualdades sociais.

De uma forma geral, esses resultados indicam a relação de mútua influência entre as crenças dos professores sobre a deficiência e suas demais crenças relacionadas à legislação de apoio aos direitos das pessoas com deficiência e a forma como veem a gestão das oficinas profissionalizantes da APAE, indicando a importância desses aspectos para a garantia do direito ao trabalho por parte das pessoas com deficiência intelectual.

\section{Considerações Finais}

Com base nos resultados encontrados nesta pesquisa, foi possível identificar que a percepção dos professores sobre a qualificação profissional é objeto de ambiguidade, ora acentuando as diretrizes e valores compartilhados pela instituição, ora explicitando concepções mais assistencialistas e fundadas em pressupostos da normalidade. Se, por um lado, a APAE apresenta em seu discurso orientações para uma profissionalização que ressalte a autonomia de seus alunos com deficiência intelectual e promova uma efetiva inclusão de seus educandos no mercado de trabalho, buscando sua independência e realização pessoal; por outro, a realidade de cada instituição depende de diversos e complexos fatores como o mercado de trabalho local e suas possibilidades, além da percepção dos professores que atuam nesse processo e que influenciam diretamente na maneira como o ensino profissionalizante é conduzido e operacionalizado.

Algumas vezes, as ações dos professores direcionam o ensino mais para uma ocupação de seus alunos do que para sua profissionalização. Embora documentos oficiais 
http://dx.doi.org/10.5902/1984686X29957

da Federação das APAEs do Estado de Minas Gerais (FENAPAE, 2006, 2011; UNIAPAE, 2017) ressaltem a busca da instituição em participar do debate político sobre os direitos e deveres das pessoas com deficiência intelectual e múltipla no país, as próprias professoras responderam que ainda é alto o número de alunos que passam muitos anos frequentando a oficina, o que leva a crer que não houve sua inserção no mundo do trabalho. As professoras também deixaram explícita a tendência das oficinas em exercer uma função mais ocupacional do que profissionalizante. E, ainda, ressalta-se a insegurança das famílias dos alunos com deficiência intelectual, que, em função das garantias do BPC, resistem à profissionalização de seus membros com receio de perdê-lo, explicitando a precariedade econômica que grande parte dessa população ainda vive no país.

Observa-se que não foi identificada uma reflexão das profissionais acerca de suas reais contribuições nas atividades ensinadas, ou seja, as professoras não questionam a efetividade da qualificação oferecida por elas, que, muitas vezes, se escondem no fato de o BPC ser um entrave à inclusão pela via do trabalho. As profissionais não apresentaram discussões acerca das questões sociais mais amplas relacionadas à dependência das famílias com relação ao BPC, apesar de reconhecerem o desejo e as potencialidades dos alunos em se formar profissionalmente. Em muitos casos, não há uma articulação da realidade local de trabalho com a qualificação profissional disponibilizada, os anseios dos alunos e a questão familiar do benefício.

Este artigo traz o relato de uma pesquisa que buscou correlacionar a percepção sobre a qualificação profissional oferecida nas APAEs mineiras com as concepções de deficiências apresentadas pelos professores, uma lacuna observada na área acadêmica, já que não foi encontrado, na literatura, nenhum outro estudo que avalie e aborde a inclusão de pessoas com deficiência intelectual em Minas Gerais sob essa perspectiva. A contribuição especial deste estudo consiste em sistematizar, num único trabalho, alguns aspectos relacionados à qualificação profissional de pessoas com deficiência intelectual, no contexto das APAEs do estado de Minas Gerais, além de mapear questões operacionais do funcionamento cotidiano destas instituições, relacionados à preparação dos alunos para o mercado de trabalho.

Ressalta-se a limitação deste estudo quanto à impossibilidade de generalização dos resultados, visto que foi realizado em algumas instituições do Estado, embora sirva como um indicativo para se pensar a qualificação profissional para pessoas com deficiência e sugira a necessidade de maior investimento na formação dos professores que oferecem 
http://dx.doi.org/10.5902/1984686X29957

essa profissionalização. Ressalta-se a necessidade de que os cursos de qualificação sejam, de fato, voltados para as necessidades do mercado de trabalho local, a fim de que realmente haja inclusão social e desenvolvimento da autonomia das pessoas atendidas nas APAEs. Destacam-se, ainda, os obstáculos para o ingresso de pessoas com deficiência intelectual no mercado de trabalho e salienta-se a necessidade de novas pesquisas que busquem trazer contribuições acerca da qualificação profissional que facilite o processo da real inclusão pela via do trabalho.

\section{Referências}

ALMEIDA, L. A. D.; CARVALHO-FREITAS, M.N.; MARQUES, A. L. Análise comparativa das percepções das pessoas com deficiência em relação à inserção no mercado formal de trabalho. In: CARVALHO-FREITAS, M. N.; MARQUES, A. L. (Org.). Trabalho e Pessoas com Deficiência: pesquisas, práticas e instrumentos de diagnóstico, 2008. p. 55-70.

ANGELA, M. B. Employment of persons with disabilities. Procedia - Social and Behavioral Sciences, n. 191, p. 979-983, 2015. Disponível em:<http://bit.ly/2cczXDd>. Acesso em: 7 jan. 2017.

ARAUJO, J. P.; SCHMIDT, A. A inclusão de pessoas com necessidades especiais no trabalho: a visão de empresas e de instituições educacionais especiais na cidade de Curitiba. Revista Brasileira de Educação Especial, Curitiba, v. 12, n. 2, p. 241-254, 2006.

BARDIN, L. Análise de Conteúdo. 1. ed. Lisboa: Edições 70, 1994. 226p.

BARNES, C.; MERCER, G.; SHAKESPEARE, T. Exploring Disability: a sociological introduction. Cambridge: Polity Press, 2005.

BRASIL. Decreto n. 1.330, de 8 de dezembro de 1994. Dispõe sobre a concessão do benefício de prestação continuada, previsto no Art. 20 da Lei n. 8.742, de 7 de dezembro de 1993, e dá outras providências. Diário Oficial da União, 1994.

BRASIL. Decreto № 6.214, de 26 de setembro de 2007. Regulamenta o Benefício de Prestação Continuada da Assistência Social devido à pessoa com deficiência e ao idoso de que trata a Lei no 8.742, de 7 de dezembro de 1993. Diário Oficial da União, 2007.

BRUCKER, D. L.; HOUTENVILLE, A. J. People with disabilities in the United States. Archives of Physical Medicine and Rehabilitation, Philadelphia, v. 96, n. 5, p. 771774, mar. 2015. Disponível em: <http://www.archives-pmr.org/article/S00039993(15)00214-2/pdf>. Acesso em: 20 maio. 2017.

CARVALHO-FREITAS, M. N.; MARQUES, A. L. A diversidade através da história: a inserção no trabalho de pessoas com deficiência. Organizações \& Sociedade, v. 14, n. 41, p. 59-78, 2007. 
http://dx.doi.org/10.5902/1984686X29957

CARVALHO-FREITAS, M. N. Inserção e gestão do trabalho de pessoas com deficiência: um estudo de caso. RAC-Revista de Administração Contemporânea, v. 13, 2009.

CARVALHO-FREITAS, M. N.; MARQUES, A. L. Formas de ver as pessoas com deficiência: um estudo empírico do construto de concepções de deficiência em situações de trabalho. Revista de Administração Mackenzie, 11(3), p. 100-129, 2010.

CARVALHO-FREITAS, M. N. Validação do inventário de concepções de deficiência em situações de trabalho (IICD-ST). Psico-Usf, v. 17, n. 1, p. 33-42, 2012.

COSTA, M. C. A. et al. Inclusão social pelo trabalho: a qualificação profissional para pessoas com deficiência intelectual. Gerais: Revista Interinstitucional de Psicologia, v. 4, n. 2, p. 200-214, 2011.

CARDOSO, L. F. V. et al. Repensando os processos de inclusão e reintegração à luz da Psicologia Social. Democracia, política e psicologia social, Florianópolis: ABRAPSO, v. 2, p. 70-86, 2017.

DINIZ, Debora; BARBOSA, Lívia; SANTOS, Wederson Rufino dos. Deficiência, direitos humanos e justiça. Sur, Rev. Internacional de Direitos Humanos, São Paulo, v. 6, n. 11, p. 64-77, 2009.

FEDERAÇÃO NACIONAL DAS APAES. Inclusão Social da Pessoa com Deficiência Intelectual e Múltipla. Brasília, 2011. Disponível em: http://www.uniapaemg.org.br/site/wpcontent/uploads/2018/04/inclusao_trabalho_renda.pdf

FEDERAÇÃO NACIONAL DAS APAEs. Projeto Especial de Qualificação. Brasília, 2006. Disponível em: http://www.apaemg.org.br/arquivo.php?arq_id=10326. Acesso em: 20 maio de 2017.

MINISTÉRIO DO TRABALHO. Características do emprego formal - Relação Anual de Informações Sociais 2016. Brasília, 2017.

PAIVA SILVA, A. I.; RIBEIRO, M. A. As Repercussões Psicossociais do Benefício de Prestação Continuada na Vida no Trabalho de Pessoas com Deficiência Física. Pesquisas e Práticas Psicossociais, ed. 6 (1), p.116-127, 2011.

RIBEIRO, M. A.; CARNEIRO, R. A inclusão indesejada: as empresas brasileiras face à lei de cotas para pessoas com deficiência no mercado de trabalho. Organizações \& Sociedade, v. 16 , n. 50, 2009.

SANTOS, W. Deficiência, desigualdade e assistência social: 0 Brasil e o debate internacional. Deficiência e discriminação, p. 117-141, 2010.

SASSAKI, R. K. Como chamar as pessoas que têm deficiência. SASSAKI, RK Vida independente; História, movimento, liderança, conceito, filosofia e fundamentos. São Paulo: RNR, p. 12-16, 2003.

SILVA, A.G.; PALHANO, E.G.S. Formação profissional: uma alternativa inclusiva para pessoas com deficiência. Caxambu: XXVIII REUNIÃO ANUAL DA ANPEd, 2005.

SUZANO, J. C. C. Concepções de deficiência e percepção do desempenho por tipo de deficiência: A perspectiva dos gestores. 2011. Dissertação de mestrado, Universidade Federal de São João del-Rei, São João del-Rei, MG, Brasil. 


$$
\text { http://dx.doi.org/10.5902/1984686X29957 }
$$

TANAKA, E. D. O.; MANZINI, E. J. O que os empregadores pensam sobre o trabalho da pessoa com deficiência? Rev. bras. educ. espec, v. 11, n. 2, p. 273-294, 2005.

UNIAPAE. Instituto de Ensino e Pesquisa de Minas Gerais. Belo Horizonte, 2017. Disponível em: http://www.uniapaemg.org.br/site.

\section{Correspondência}

Mariela Cristina de Aguiar Costa - Universidade Federal de São João del-Rei, Praça Frei Orlando, 170 - Centro, CEP: 36307-352, São João del-Rei, Minas Gerais, Brasil.

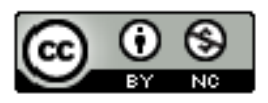

This work is licensed under a Creative Commons Attribution-NonCommercial 4.0 International (CC BY-NC 4.0) 